\title{
The combination of glycyrrhizin and lamivudine can reverse the cisplatin resistance in hepatocellular carcinoma cells through inhibition of multidrug resistance-associated proteins
}

\author{
TAKAHIRO WAKAMATSU, YOSHITSUGU NAKAHASHI, DAISAKU HACHIMINE, \\ TOSHIHITO SEKI and KAZUICHI OKAZAKI
}

Third Department of Internal Medicine, Division of Gastroenterology and Hepatology, Kansai Medical University, 2-3-1 Shinmachi, Hirakata 573-1191, Japan

Received May 9, 2007; Accepted August 3, 2007

\begin{abstract}
Cisplatin is commonly used as a chemotherapeutic agent for hepatocellular carcinoma (HCC). However, it cannot satisfactorily improve the survival rate for patients with advanced HCC due to intrinsic or acquired drug resistance caused by multidrug resistance-associated proteins (MRPs). To clarify whether or not glycyrrhizin and lamivudine have modulator effects on HCC treated with cisplatin, we established a cisplatin-resistant Huh7 HCC cell line and analyzed the mRNA expression of MRPs in the resistant cells. The resistant cells showed 14.1-fold higher resistance to cisplatin, and they expressed higher levels of MRP2 (6.29-fold), MRP3 (3.2-fold), MRP4 (11.3-fold) and MRP5 (3.39-fold) mRNAs than the wild-type cells by using real-time PCR. However, MRP1, MDR1 and GST- $\pi$ mRNA were not induced. Compared with the treatment of the resistant cells with cisplatin only, co-treatment with cisplatin and glycyrrhizin or lamivudine significantly decreased the cell viability to $76.8 \%$ and $79.5 \%$, respectively. Co-treatment with cisplatin and both glycyrrhizin and lamivudine further decreased the cell viability to $65.1 \%$. Intracellular concentration of cisplatin in the resistant cells decreased to $36.4 \%$ of that of the wild-type cells while it increased to $47.7 \%$ or $48.4 \%$ when glycyrrhizin or lamivudine were added separately, or $60 \%$ when they were added together. Our findings indicate the following: i) high expression of MRP2, MRP3, MRP4 and MRP5 decreases cisplatin accumulation in cisplatin-resistant HCC cells and contributes to cisplatin resistance; ii) glycyrrhizin and/or lamivudine accumulate cisplatin in resistant cells by inhibiting the cisplatin efflux from the cells; and iii) glycyrrhizin and
\end{abstract}

Correspondence to: Dr Yoshitsugu Nakahashi, Third Department of Internal Medicine, Division of Gastroenterology and Hepatology, Kansai Medical University, 2-3-1 Shinmachi, Hirakata 573-1191, Japan

E-mail: nakahash@hirakata.kmu.ac.jp

Key words: multidrug resistance-associated proteins, hepatocellular carcinoma, cisplatin, glycyrrhizin, lamivudine lamivudine both act as modulators and have the effect of reversing cisplatin resistance, and co-treatment with glycyrrhizin and lamivudine enhances modulator activity in reversing the cisplatin resistance.

\section{Introduction}

Hepatocellular carcinoma (HCC) is one of the most common cancers in the world, especially in Asia and Africa (1), and infection of hepatitis B virus (HBV) is a high risk factor of HCC. The treatment of HCC remains unsatisfactory because chemotherapy, either as a single agent or by a multidrug regimen, does not prolong life in most cases (2) and is often impeded by a marked drug resistance in the patient. Patients with HCC were classified into two groups depending on response to chemotherapy: the first group had an intrinsic drug resistance and members were insensitive to drug treatment at the onset of therapy, and the second group acquired drug resistance after the first treatment with a chemotherapeutic agent. This multidrug resistance (MDR) can be caused by expression of plasma membrane transporters belonging to the MDR/P-glycoprotein family. These transporters mediate ATP-dependent efflux of chemotherapeutic drugs across the plasma membrane (3). As MDR1 mRNA is spontaneously expressed in HCC (4), inhibitors of MDR1 can theoretically modulate drug effects. However, inhibitors of MDR1, such as verapamil, have not improved the efficacy of chemotherapy on HCC (5).

Studies on cell lines derived from HCC indicated that the MDR phenotype is attributable not only to expression of the MDR1 gene but also to other mechanisms (6). Multidrug resistance-associated proteins (MRPs), which are distinct from MDR/P-glycoproteins, are integral membrane glycoproteins, some of which confer resistance to chemotherapeutic agents (7). The first cloned member of this family is MRP1 (ABCC1), which was demonstrated to confer resistance to a number of drugs, including doxorubicin, vincristine, and etoposide (8). Since the cloning of MRP1, eight new MRP proteins have been cloned (9). MRP1 is expressed in many different cell types, although not in significant amounts in human hepatocytes (10). In hepatocytes, additional MRP isoforms, MRP2 (ABCC2), MRP3 (ABCC3), MRP4 (ABCC4) and MRP5 (ABCC5) have been identified (7). MRP2, which carries organic anions into 
the bile, is known as the canalicular multispecific organic anion transporter (cMOAT) (11). MRP2 confers resistance to several chemotherapeutic agents including anthracycline, vinca alkaloids, etoposide, camptotesine, and methotrexate (12). MRP3 is also an organic anion transporter that can transport glucuronide conjugates, glutathione-S-conjugates, and monoanionic bile salts (13). MRP4 and MRP5 confer a unique drug resistance phenotype and transport representatives of a different class of amphipathic conjugates in that both transporters have been implicated in resistance to and transport of purine and nucleotide analogues. Unlike MRP1 and MRP2, MRP4 and MRP5 do not confer resistance against anthracyclines, vinca alkaloids or epipodophyllotoxins. MRP4 and MRP5, however, induce resistance to purine analogues and other nucleoside-based antiviral drugs $(14,15)$.

Cisplatin is commonly used as a chemotherapeutic agent for HCC although it cannot satisfactorily improve the survival rate for the patients with advanced HCC due to development of drug resistance (16). In lung cancer, decreased accumulation of cisplatin was observed in cisplatin-resistant cell lines from non-small cell lung cancer cells, and the amount of intracellular cisplatin showed a correlation with the sensitivity to cisplatin (17). In cases of lung cancer, MRP2 has been reported to be involved in the development of cisplatin resistance. Human MRP2 mRNA is upregulated by 4- to 6-fold in cisplatinresistant cell lines derived from various human tumors, which resulted in decreased drug accumulation (18). Furthermore, Koike et al transfected an expression vector containing MRP2 antisense cDNA into the human hepatoma cell line, and showed that the transfectants displayed an increased sensitivity to cisplatin (19). In addition to MRP2, MRP4 and MRP5 were overexpressed in cisplatin-resistant small lung cancer cells in both cell lines (20) and in vivo (21).

Glycyrrhizin, extracted from the roots of Glycyrrhizae globa, is widely administered to chronic liver disease patients in Japan because of its anti-inflammatory effects on the hepatocytes (22). Glycyrrhizin in its glucuronate form is a substrate of MRP2 (11). Lamivudine, which was first used to treat human immunodeficiency virus (HIV) infection and was approved for the treatment of HBV infection in 1999 (23), is a nucleotide analogue and substrate of MRP4 and MRP5 $(14,15)$.

In the present study, to clarify whether glycyrrhizin and lamivudine have modulator effects on HCC treated with cisplatin or not, we established a cisplatin-resistant hepatocellular carcinoma cell line and analyzed mRNA expression of MRPs in the resistant cells.

\section{Materials and methods}

Cell lines and culture. The human hepatoma cell line, Huh7, was established from a well-differentiated hepatocellular carcinoma (24). Cells were cultured in Dulbecco's modified Eagle's medium (Gibco, Grand Island, NY) supplemented with $5 \%$ fetal calf serum and $1 \%$ penicillin-streptomycin mixed solution (10000 U PCs and $10 \mathrm{mg} \mathrm{SM} / \mathrm{ml}$ in $0.85 \% \mathrm{NaCl}$, Nacalai tesque Inc., Kyoto, Japan), and maintained at $37^{\circ} \mathrm{C}$ in a humidified atmosphere of $5 \% \mathrm{CO}_{2}$ and $95 \%$ air. Approximately $1.0 \times 10^{6}$ viable cells were seeded in a $100-\mathrm{mm}$ dish, and the medium was replaced with $7 \mathrm{ml}$ of fresh medium after $24 \mathrm{~h}$. After $72 \mathrm{~h}$, the cells were sub-cultivated by $0.5 \mathrm{~g} / \mathrm{l}$ trypsin/0.53 mmol/1 EDTA mixed-solution (Nacalai tesque Inc.), and seeded to another 100-mm dish.

Establishment of the resistance of the cells to cisplatin. A low concentration $(10 \mathrm{ng} / \mathrm{ml})$ of cisplatin (Sigma-Aldrich, St. Louis, USA) was added to the medium. The cells that survived after $72 \mathrm{~h}$ of exposure to cisplatin were sub-cultivated and seeded in another plate. Cells were judged to have acquired resistance when they were able to maintain logarithmic growth upon addition of cisplatin to the culture solution. The culture solution was sub-cultivated and left unexposed to further cisplatin for approximately two weeks before verifying resistance. Further resistance was established by gradually raising the concentration of cisplatin in the culture solution (25). For the present study, cells were cultured to acquire a target resistance of $5 \mu \mathrm{g} / \mathrm{ml}$ cisplatin.

Cytotoxicity of cisplatin. Cytotoxicity of cisplatin was measured by Alamar blue ${ }^{\mathrm{TM}}$ assay (Trek diagnostic systems Ltd., West Sussex, UK), which is a modified method of MTT assay (26). All assays were performed in triplicate. Wild-type Huh7 and the cisplatin-resistant Huh7 cell line were seeded onto a 96well plate at a cell density of $5 \times 10^{2} /$ well, and exposed to cisplatin after $24 \mathrm{~h}$ upon exchanging the medium. Alamar blue $^{\mathrm{TM}}$ assay was performed after $24,48,72,96$, and $120 \mathrm{~h}$ to obtain the proliferation curves for both the wild-type cells and the resistant cells. Cytotoxicity of cisplatin was measured by $\mathrm{IC}_{50}$, the concentration corresponding to $50 \%$ survival.

RNA isolation and cDNA synthesis. Total RNAs were extracted from each cell line (the wild-type cells and the resistant cells) $72 \mathrm{~h}$ after adding glycyrrhizin and lamivudine by an RNAqueous-4PCR kit (Ambion Inc., TX, USA) according to the manufacturer's protocol. First-strand cDNA was synthesized from $1 \mu \mathrm{g}$ of total RNA by reverse transcription with a SuperScript ${ }^{\mathrm{TM}}$ first-strand synthesis system kit (Invitrogen, CA, USA), according to the manufacturer's instructions.

Polymerase chain reaction (PCR). PCR was performed by a thermal cycler (i-Cycler; Bio-Rad Lab., Japan). The PCR primers and each annealing temperature were as follows: MDR1, a 255-bp product was generated using 5'-TCACCTT CGTCAGCTACTTCGG-3' (forward primer) and 5'-CAGGA GGTCACAGCCGACTTTAAAC-3' (reverse primer) at an annealing temperature of $60^{\circ} \mathrm{C}$; GST- $\pi$, a 250 -bp product was generated using 5'-CTCACTCAAAGCCTCCTG-3' (forward primer) and 5'-CTGCCTTCACATAGTCATCC-3' (reverse primer) at an annealing temperature of $60^{\circ} \mathrm{C}$; MRP1, a 294-bp product was generated using 5'-CGGAAACCATCCACGACC CTAATC-3' (forward primer) and 5'-ACCTCCTCATTCGCA TCCACCTTG-3' (reverse primer) at an annealing temperature of $60^{\circ} \mathrm{C}$; MRP2, a 755-bp product was generated using 5'-AT GGCAGTGAAGAAGAAGACGATGAC-3' (forward primer) and 5'-GACGATGATGGTGAAGACAGGAGTGG-3' (reverse primer) at an annealing temperature of $65^{\circ} \mathrm{C}$; MRP3, a 752-bp product was generated using 5'-AACTATGCCCCCGATG AGGACCAA-3' (forward primer) and 5'-AGAGTGGAGA TGGCGTTGAAGAAG-3' (reverse primer) at an annealing temperature of $65^{\circ} \mathrm{C}$; MRP4, a 696-bp product was generated 
using 5'-CGGGCATACAAAGCAGAAGAGAGG-3' (forward primer) and 5'-CAGTTCCTCATCCGTGTGCTCCTT-3' (reverse primer) at an annealing temperature of $68^{\circ} \mathrm{C}$; and MRP5, a 401-bp product was generated using 5'-ATCAAGC AAGGAAGCGGGAACACC-3' (forward primer) and 5'-GC CACAAGGAACCACGGGAAGACT-3' (reverse primer) at an annealing temperature of $65^{\circ} \mathrm{C}$. Primers were designed based on the reported sequences $(27,28)$. The $B$-actin gene was used as the internal control. For a typical PCR run $1 \mu 1$ of the synthesized cDNA in a total volume of $50 \mu 1$ reaction mixture containing 1 unit rTaq DNA polymerase (Toyobo, Osaka, Japan), 1X PCR buffer, $2 \mathrm{mM} \mathrm{MgCl}_{2}, 0.2 \mathrm{mM}$ dNTPs, and $500 \mathrm{nM}$ each of forward and reverse primers, was denatured at $95^{\circ} \mathrm{C}$ for $30 \mathrm{sec}$, annealed for $30 \mathrm{sec}$, and extended at $72^{\circ} \mathrm{C}$ for $30 \mathrm{sec}$ for 40 cycles. PCR products were verified by eletrophoretic analysis in $2 \%$ agarose gel.

Real-time PCR. Quantitative real-time PCR was performed with $\mathrm{iQ}^{\mathrm{TM}}$ SYBR-Green Supermix (Bio-Rad Lab., Japan) using a total volume of $50 \mu 1$ reaction mixture containing $1 \mu \mathrm{l}$ of the synthesized cDNA. Real-time PCR was carried out using the i-Cycler iQ detection system (Bio-Rad Lab., Japan). The cycling conditions were the same as for normal PCR. The melt curve program was performed immediately after completion of PCR by increasing the temperature by $0.5^{\circ} \mathrm{C}$ from $55^{\circ} \mathrm{C}$ to $90^{\circ} \mathrm{C}$.

Cytotoxicity of cisplatin co-administered with glycerrhizin and/or lamivudine as modulators. Lamivudine (2'3'-dideoxy3'-thiacytidine, 3TC), was purchased from GlaxoSmithkline (Tokyo, Japan) and glycyrrhizin was kindly donated by Minophagen Pharm. (Tokyo, Japan). Each cell line was divided into five groups: i) medium only (no medication), ii) cisplatin only (addition of $5 \mu \mathrm{g} / \mathrm{ml}$ cisplatin), iii) cisplatin and glycyrrhizin (addition of 5 and $100 \mu \mathrm{g} / \mathrm{ml}$, respectively), iv) cisplatin and lamivudine (addition of 5 and $1 \mu \mathrm{g} / \mathrm{ml}$, respectively), and v) cisplatin, glycyrrhizin and lamivudine (addition of 5, 100, and $1 \mu \mathrm{g} / \mathrm{ml}$ respectively). The cell-lines were seeded onto a 96-well plate at a cell density of $5 \times 10^{2 /}$ well. After $24 \mathrm{~h}$, the medium was exchanged with $200 \mu \mathrm{l}$ of medicated medium. Following medium exchange, the celllines were cultured for $96 \mathrm{~h}$ before the number of cells was examined by Alamar blue assay, performed in triplicate. Cytotoxicity was measured as cell viability relative to viability in the cisplatin-only group.

Examination of the intracellular concentration of cisplatin. Seventy-two hours after adding the modulator agents, 5.0$7.0 \times 10^{6}$ cells were collected from each cell line. The concentration of each medicine was the same as that of above. The cells were washed twice by PBS(-), then dispersed in $50 \mu 1$ PBS(-), and sonicated (Bioruptor, Cosmo Bio Co.Ltd, Tokyo Japan). The amount of cisplatin per cell in each group was examined by measuring the concentration of cisplatin in cellcrushed liquids. Measurement of cisplatin was performed with atomic absorption spectrophotometry which sets platinum to the marker (29).

Statistical analysis. Statistical significance was established using the paired two-tailed Student's t-test.

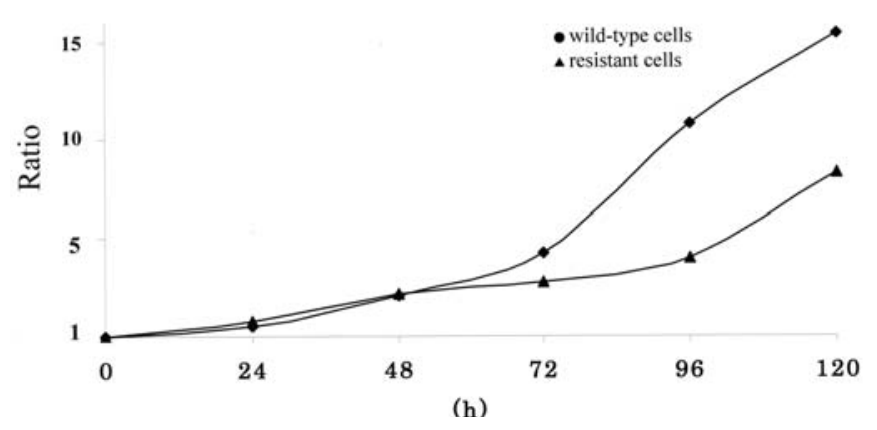

Figure 1. Proliferation curve of the wild-type cells and the resistant cells The ratio with the number of cells at the start of cultivation is plotted.

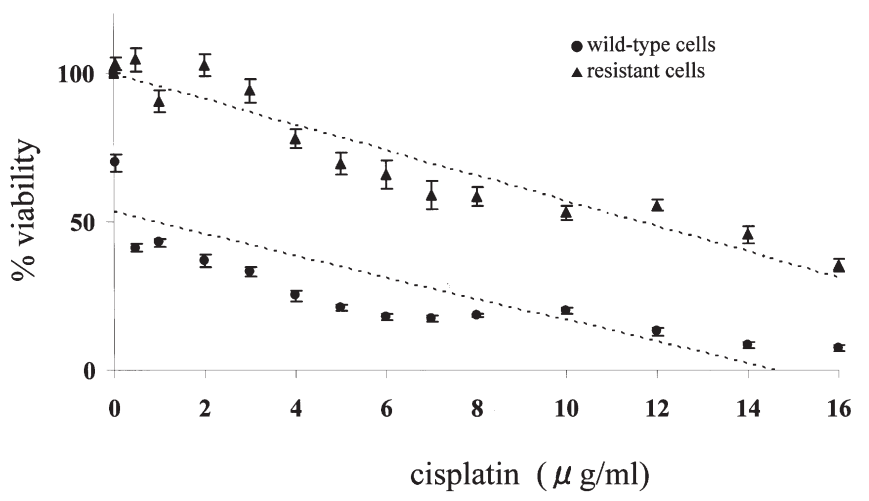

Figure 2. The cytotoxic effects of cisplatin on wild-type cells and resistant cells. The $\mathrm{IC}_{50}$ of each cell line was calculated by drawing the approximation straight line (dotted line) which was created using the method of least-squares. Each point represents the mean $\pm \operatorname{SE}(n=3)$.

\section{Results}

Establishment of the cisplatin-resistant cell line. Logarithmic growth of the wild-type cells and the resistant cells was measured for $120 \mathrm{~h}$ following inoculation. Proliferation potency between the wild-type cells and the resistant cells was comparable after approximately $48 \mathrm{~h}$ of growth, after which point the wild-type cells were superior in their proliferation potential, as demonstrated by cell concentrations double that of the resistant cells (Fig. 1). After $72 \mathrm{~h}$, the $\mathrm{IC}_{50}$ value of cisplatin for the wild-type cells was $0.82 \mu \mathrm{g} / \mathrm{ml}$ and $11.6 \mu \mathrm{g} / \mathrm{ml}$ for the resistant cells (Fig. 2). The resistant cells showed a 14.1-fold increased resistance to cisplatin. Compared with cisplatin-free control groups, the $\%$ viability of the wildtype cells treated with $5 \mu \mathrm{g} / \mathrm{ml}$ of cisplatin decreased in a time-dependent manner to $52.6 \pm 3.79,39.6 \pm 3.24,29.0 \pm 2.97$, and $24.0 \pm 3.57 \%$ at $48,72,96$ and $120 \mathrm{~h}$, respectively. On the other hand, the \% viability remained unchanged for the resistant cells over the course of the culture (Fig. 3).

PCR of the MRP family in wild-type and resistant cells. RT-PCR products for MDR1, GST- $\pi$, MRP1, MRP2, MRP3, MRP4 and MRP5 are shown for both the wild-type and resistant cells in Fig. 4. Both cell lines showed similar expression of the MDR1, GST- $\pi$, MRP1, MRP2, MRP3, MRP4 and MRP5 genes. Real-time PCR results confirmed that the mRNA expression of MDR1, GST- $\pi$ and MRP1 remained 


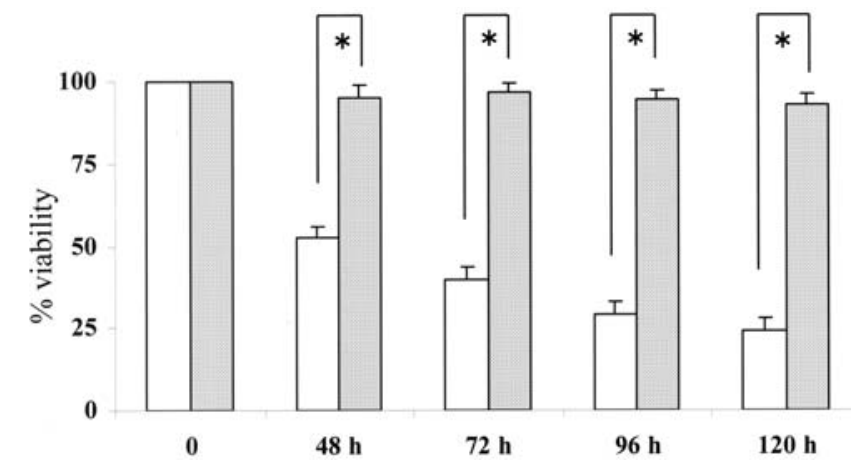

Figure 3. Suppression of the proliferation of wild-type and resistant cells by cisplatin. Each bar represents the mean \pm SE $(n=8)$. Empty bars, wild-type cells $\mathrm{x}$ cisplatin; filled bars, resistant cells $\mathrm{x}$ cisplatin. ${ }^{*} \mathrm{P}<0.01$.

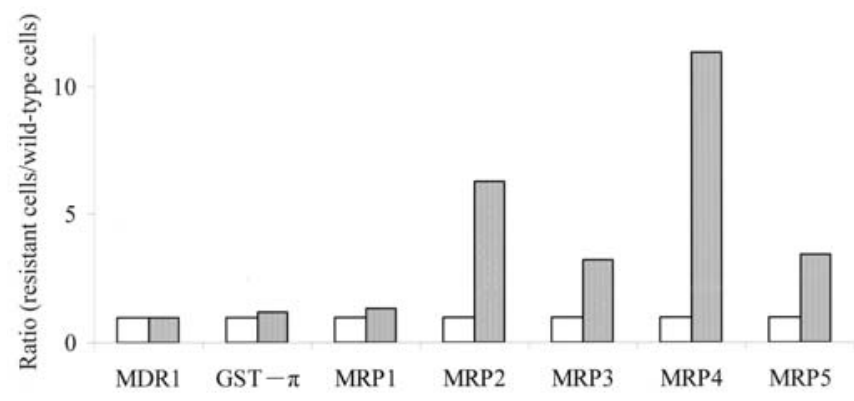

Figure 5. Quantitative real-time PCR analysis of the mRNA expression of the MRP family in wild-type and resistant cells. The ratio of mRNA of the MRP family between the wild-type and resistant cells was examined by using real-time PCR. Each result represents the average value of 3 to 9 trials. Empty bars, wild-type cells; filled bars, resistant cells.

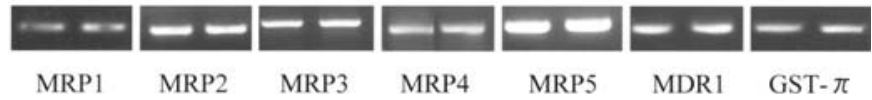

Figure 4. Electrophoretic analysis by reverse transcription-polymerase chain reaction of MRP transcripts expressed in wild-type and resistant cells. Left lane, wild-type cells; right lane, resistant cells.

unchanged between the wild-type cells and resistant cells (Fig. 5). However, the mRNA expression of MRP2, MRP3, MRP4 and MRP5 was significantly different between the two cell lines $(\mathrm{P}<0.01)$. The resistant cells showed up-regulation of MRP2 (6.29-fold), MRP3 (3.2-fold), MRP4 (11.3-fold) and MRP5 (3.39-fold), as compared to the wild-type cells.

Modulatory effects of glycyrrhizin and lamivudine on the cisplatin-induced cytotoxicity to the resistant cells. We first confirmed the absence of cytotoxic effects from glycyrrhizin or lamivudine treatment alone, on both the wild-type cells and the resistant cells. Compared with the drug-free group, the $\%$ viability of cells in the glycyrrhizin $(100 \mu \mathrm{g} / \mathrm{ml})$ addition group and the lamivudine $(1 \mu \mathrm{g} / \mathrm{ml})$ addition group was $97 \%$ and $99 \%$ at $96 \mathrm{~h}$, respectively (data not shown).

Next, we investigated the cytotoxic effects of combined cisplatin and glycyrrhizin or lamivudine treatment on the resistant cells, expressed as a relative ratio (\%) of viability for resistant cells treated with cisplatin alone. Co-treatment with cisplatin and glycyrrhizin decreased the relative viability to $76.8 \pm 3.39 \%$ at $96 \mathrm{~h}$ (Fig.6). Similarly, the \% viability for co-treatment with cisplatin and lamivudine diminished to $79.5 \pm 3.17 \%(\mathrm{P}<0.01)$. Moreover, co-treatment with cisplatin, glycyrrhizin and lamivudine led to a marked decrease in relative viability to $65.1 \pm 3.46 \%(\mathrm{P}<0.01)$. These results indicate that glycyrrhizin and lamivudine co-operatively decrease the viability, as compared to treatment with glycyrrhizin or lamivudine alone.

Measurement of the intracellular cisplatin concentration of resistant cells. The intracellular cisplatin concentration of the resistant cells was significantly decreased to $36.4 \pm 4.97 \%$ of that of the wild-type cells (Fig. 7). However, intracellular cisplatin concentrations of the resistant cells increased to $47.7 \pm 0.36 \%$ by addition of glycyrrhizin and to $48.4 \pm 0.78 \%$

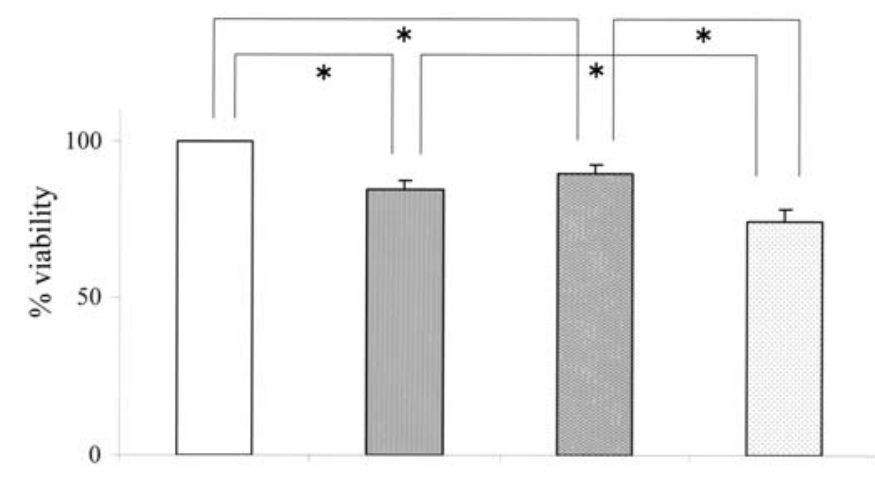

(a)

(b)

(c)

(d)

Figure 6. Modulatory effects of glycyrrhizin and lamivudine on the cisplatininduced cytotoxicity to the resistant cells. (a) Addition of cisplatin only. (b) Addition of cisplatin and glycyrrhizin. (c) Addition of cisplatin and lamivudine. (d) Addition of cisplatin, glycyrrhizin and lamivudine. Each bar represents the mean \pm SE $(n=8)$. ${ }^{*} \mathrm{P}<0.01$.

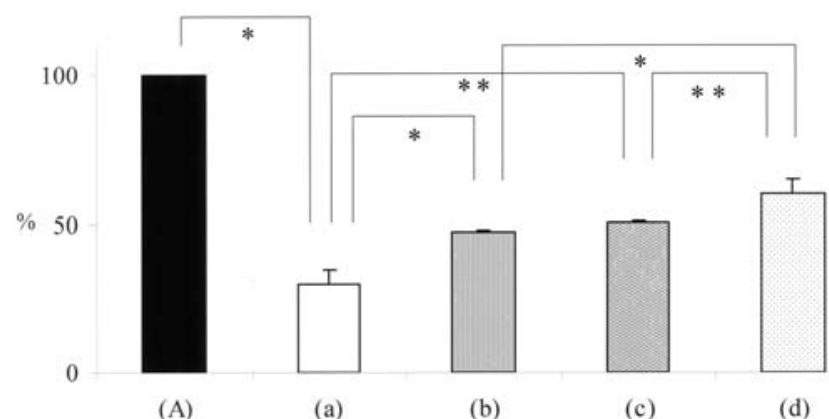

Figure 7. Comparison of the intracellular cisplatin concentration of the resistant cells. (A) Intracellular cisplatin concentration when adding cisplatin to the wild-type cells was $100 \%$. (a) Addition of cisplatin only. (b) Addition of cisplatin and glycyrrhizin. (c) Addition of cisplatin and lamivudine. (d) Addition of cisplatin, glycyrrhizin and lamivudine. Each bar represents the mean \pm SD $(n=3) .{ }^{*} \mathrm{P}<0.01,{ }^{* *} \mathrm{P}<0.05$.

by addition of lamivudine. Furthermore, the concentration increased to $62.0 \pm 4.8 \%$ by co-administering glycyrrhizin and lamivudine. These findings suggest that glycyrrhizin and lamivudine co-operatively increase intracellular cisplatin concentration in the resistant cells treated with cisplatin as the modulator. 


\section{Discussion}

We have established a cisplatin-resistant Huh7 hepatocellular carcinoma cell line. The resistant cells showed a 14.1-fold increased resistance to cisplatin, as compared to wild-type cells (Fig. 2). The resistant cells also expressed higher levels of MRP2, MRP3, MRP4 and MRP5 mRNAs with 6.29-, 3.2-, 11.3- and 3.39-fold increases as measured by real-time PCR (Fig. 5). However, MRP1, MDR1 and GST- $\pi$ mRNAs were not induced.

Although the precise mechanism remains unknown, it appears that cisplatin resistance is multifactorial, as characterized by decreased cisplatin accumulation across the plasma membrane, increased intracellular detoxification, and increased DNA repair ability from DNA damage (30-32).

Expression of the MDR1 gene has been associated with resistance to adriamycin and vincristine, but not to cisplatin $(33,34)$. However, expression of the MDR1 gene was shown to be upregulated by cisplatin in myelogenous leukemia cells (35) and HCC cell lines including Huh7 cells (28). In HCC, MRP1 is unlikely to be involved in the MDR phenotype, because MRP1 mRNA expression is very low in the liver (10). In the present study, MDR1 and MRP1 mRNAs were not significantly upregulated in cisplatin-resistant Huh7 cells (Fig. 5), suggesting that MDR1 and MRP1 are not involved in the resistance to cisplatin in the resistant cell line.

The mechanism of cellular detoxification of many harmful xenobiotics involves intracellular conjugation of the xenobiotic-reactive center with glutathione, glucuronide, or sulfate (36). These conjugations generally render the xenobiotics less chemically reactive and, hence, less toxic to the cell. Glutathione conjugation reactions, catalyzed by the many isozymes of glutathione S-transferase (GST), are particularly important for detoxification of electrophilic xenobiotics, which includes many carcinogens and cytotoxic drugs (37). The GST $-\pi$ gene, which encodes an isozyme of GST, conjugates glutathione to toxic compounds for detoxification (38). Cisplatin is also detoxicated by GST, however GST- $\pi$ mRNA levels were not induced in the cisplatin-resistant Huh7 cells in the present study (Fig 5). These findings suggest that glutathione conjugation reaction is a minor determinant of the cisplatin resistance in the resistant Huh7 cells.

MRP2, which localizes to hepatocyte canalicular membranes, is an organic anion transporter (11). MRP2 is a major transporter of bilirubin, glucuronides, and other organic anions, from the liver into the biliary tract. It is also able to transport anticancer agents, including cisplatin. Human MRP2 mRNA expression has been shown to be 4- to 6-fold higher in cisplatin-resistant cell lines derived from various human tumors exhibiting decreased drug accumulation (18). Downregulation of MRP2 mRNA via MRP2 antisense cDNA enhances their sensitivity to cisplatin (19). In the present study, MRP2 mRNA was induced 6.29-fold in the resistant cells when compared to wild-type cells. Our data also suggests that increased expression of MRP2 correlates with cisplatin resistance in the cisplatin-resistant Huh7 cells, in agreement with previous reports.

MRP3 is also an organic anion transporter capable of transporting anticancer agents and is localized to the hepatocyte basolateral membranes. It has been reported that cisplatin slightly increases MRP3 mRNA expression in HepG2 cells $(\sim 1.5$-fold $)$ and antisense RNA of MRP3 increases cellular sensitivity to cisplatin (39). However, overexpression of MRP3 cDNA results in resistance to etoposide and teniposide, but not to other drugs affected by multidrug resistance $(40,41)$. Several studies have also tried to link MRP3 expression in cancer cell lines and patient-derived tumor samples to resistance against anticancer agents. The results in cancer cell lines were either negative $(10,42)$ or the resistance spectrum found did not fit the known drug resistance spectrum associated with MRP3 (43). Based on the low levels of resistance found in MRP3 cDNA transfectant cells and the narrow spectrum of anticancer agents to which MRP3 mediates resistance, it is speculated that MRP3 plays a limited role in clinically relevant drug resistance. In the present study, we showed that MRP3 mRNA expression was increased in the resistant cells by 3.2 -fold. Our data suggests that elevated MRP3 levels correlate with cisplatin resistance in the cisplatin-resistant Huh7 cells.

Within the MRP subfamily, MRP4 and MRP5 are unique. All lack the third N-terminal transmembrane domains (TMDs) which are known as TMD0 but retain the hydrophilic linker, known as the L0 linker (9). MRP4 and MRP5 share $<40 \%$ similarity with the other MRP proteins. Both proteins also share $<40 \%$ similarity with each other. Nevertheless, MRP4 and MRP5 are much more similar to the other MRPs than to other members of the MRP family. MRP4 is localized to the basolateral membrane in human, rat, and mouse hepatocytes (44) and is widely expressed, with mRNA levels ranging from very high in the prostate to barely detectable in the liver (45). MRP4 is also present in many human cancer cell lines (10). MRP4 was induced in a cisplatin-resistant small lung cancer cell line. This induction has been associated with resistance to nucleoside analogues, such as azidothymidine (AZT), 6mercaptopurine (6-MP) and 6-thioguanine (6-TG) (14). The resistance is due to decreased intracellular drug concentration as a result of decreased drug efflux. Norris et al (46) have suggested a correlation between increased MRP4 levels and tumor prognosis in patients with primary neuroblastoma. The authors attribute this correlation to the ability of MRP4 to transport irinotecan and its active metabolite SN38. We showed that MRP4 mRNA was expressed at a higher level in the resistant cells (11.3-fold). These findings suggest that MRP4 expression correlates with cisplatin resistance in Huh7 cells.

MRP5 is ubiquitously expressed in human systemic organs, with extremely high levels observed in skeletal muscle, brain, and heart (10). MRP5 is thought to be localized in the basolateral membrane of most tissues, and functions to efflux conjugated compounds from the cells (47). When MRP5 is transfected into drug-sensitive cells, it confers resistance to antifolate drugs such as methotrexate and to nucleoside-based drugs such as 6-MT, 6-TG, PMEA, AZT, cytosine arabinoside, 5-fluorouracil, and gemcitabine $(15,48)$. MRP5-expressed inside-out membrane vesicles demonstrated the direct transport of the monophosphate metabolites of nucleoside-based drugs, such as 5-fluorouracil and 6-thioguanine $(48,49)$. In vivo, upregulation of the MRP5 gene has been observed as a result of exposure to cisplatin in lung cancers (21). Pratt et al (48) found a three-fold increase in resistance to cisplatin and oxaliplatin in their MRP5 transfectants, as well as a two-fold increase in resistance to doxorubicin. However, no cisplatin or doxorubicin 
resistance was observed by McAleer et al (49) and Wijnholds et al (15). Wijnholds et al conversely found some resistance to etoposide/teniposide that was not identified elsewhere (15). It is unlikely that MRP5 will obviously contribute to MDR or platin drug resistance in the clinic. In the present study, we showed that MRP5 mRNA expression increased 3.39-fold in the resistant cells, suggesting a correlation with cisplatin resistance in Huh7 cells.

Several investigators have reported that decreased accumulation of cisplatin was observed in cisplatin-resistant cell lines (20). Decreased accumulation of cisplatin was observed in cisplatin-resistant cell lines from non-small cell lung cancer (NSCLC), and a good correlation was found between the amount of intracellular platinum and the sensitivity to cisplatin in lung cancer cell lines. This evidence suggests that intracellular accumulation is a major determinant of cisplatin resistance in NSCLC (50). It was demonstrated that MRP2 and MRP3 mRNA expression was at least 10-fold higher than MRP1 mRNA expression in HCC cells. MRP2 and MRP3 were localized to the plasma membrane of these carcinoma cells, whereas MRP1 was expressed only on the intracellular membranes of some HCCs. Both MRP2 and MRP3 may thus contribute to the chemoresistance (51). Other groups reported that MRP2 acts as an important transporter in chemoresistance, with mRNA and protein expression levels generally maintained or even increased in human HCC (52). However, the expression levels of MRP4 and MRP5 in HCC have remained unclear. In the present study, we first showed that the cisplatin-resistant HCC cells expressed higher levels of MRP2, MRP3, MRP4 and MRP5 mRNA than the wild-type cells by using real-time PCR (Fig. 5). Also, the intracellular cisplatin concentration of the resistant cells was significantly decreased, compared with the wild-type cells (Fig.7). Our results suggest that the high expression of MRP2, MRP3, MRP4 and MRP5 decreases the cisplatin accumulation in the resistant cells and contributes to the cisplatin resistance.

Next, the modulatory effects of glycyrrhizin and lamivudine on the cisplatin-induced cytotoxicity were examined in the resistant cells (Fig. 6). Compared with the cisplatin treatment alone, cell viability following co-treatment with cisplatin and glycyrrhizin decreased to $76.8 \%$. Similarly, co-treatment with cisplatin and lamivudine reduced cell viability to $79.5 \%$. Furthermore, co-treatment with cisplatin, glycyrrhizin and lamivudine significantly lowered the viability of the resistant cells to $65.1 \%$. These findings suggest that glycyrrhizin and lamivudine significantly reverse the effect of cisplatin resistance by acting as modulators, and that co-treatment with glycyrrhizin and lamivudine results in more potent modulator activity.

We also showed that the intracellular cisplatin concentration of the resistant cells was significantly decreased to $36.4 \%$ with cisplatin alone and increased to $47.7 \%$ by addition of glycyrrhizin compared to wild-type cells (Fig. 7). Although glycyrrhizin does not have antiviral properties, it primarily acts as an anti-inflammatory or cytoprotective drug. It improves mortality and liver function in patients with sub-acute hepatic failure, chronic hepatitis, and cirrhosis with activity. Glycyrrhizin may prevent the development of hepatocellular carcinoma in patients with chronic hepatitis C (53).
Glycyrrhizin is a glucuronate form, and is also a substrate of MRP2 and MRP3 (54). Our results suggest that glycyrrhizin could increase the intracellular concentration of cisplatin in the resistant cells. We also demonstrated that the intracellular concentration of cisplatin in the resistant cells was increased to $48.4 \%$ of that of the wild-type cells by addition of lamivudine (Fig. 7). Lamivudine, a nucleoside analogue which directly inhibits HBV DNA polymerase, was first developed as a reverse transcriptase inhibitor for use in HIV infection (55). The efficacy of lamivudine as an anti-HBV agent has been confirmed using randomized controlled trials in a wide variety of clinical situations. It has been shown to reduce HBV DNA levels and serum transaminases, and improve histological indices in patients with both $\mathrm{HBeAg}$-positive and -negative diseases (56). Lamivudine could increase the concentration of cisplatin in the resistant cells because it is a nucleoside analog and the substrate of MRP4 and MRP5, which are nucleoside analog pumps. Moreover, co-treatment with glycyrrhizin and lamivudine increased the intracellular concentration of cisplatin in the resistant cells to $62.0 \%$ of that of the wild-type cells (Fig. 7). These findings suggest that glycyrrhizin is a competitive substrate for MRP2 and MRP3 and lamivudine is a competitive substrate for MRP4 and MRP5. Therefore, glycyrrhizin and lamivudine act as modulators to reverse the effects of cisplatin resistance by inhibiting cisplatin efflux from the resistant HCC cells.

Pharmacological reversal of the MRP family by some compounds has been demonstrated in cell or tissue culture, however there is minimal evidence of their therapeutic effectiveness in clinical trials or against solid tumors in animals. To date, there are no potent modulators of cisplatin resistance available in the clinic $(9,11)$. One main reason for this is that the concentration of modulators in serum required for reversal cannot be achieved. Transcatheter arterial chemoembolization (TACE) improves the survival of patients with unresectable HCC and has become the standard treatment (57). TACE can deliver high concentrations of cancer chemotherapeutic agents directly to the HCC via the hepatic arterial route. Glycyrrhizin and lamivudine are well known and widely used as therapeutic agents for chronic liver diseases. TACE with cisplatin, co-administered with glycyrrhizin and lamivudine via the hepatic artery, can be performed safely and may improve the survival of patients with advanced HCC, though further studies are necessary.

In conclusion, our findings indicate that elevated expression of MRP2, MRP3, MRP4 and MRP5 decreases the cisplatin accumulation in the cisplatin-resistant HCC cells and contributes to the resistance, and the combination of glycyrrhizin and lamivudine inhibit the cisplatin efflux from the HCC cells, acting as modulators to reverse cisplatin resistance.

\section{References}

1. Llovet JM: Hepatocellular carcinoma. Lancet 362: 1907-1917, 2003.

2. Schafer DF and Sorrell MF: Hepatocellular carcinoma. Lancet 353: 1253-1257, 1999.

3. Goldstein LJ, Galski H, Fojo A, Willingham M, Lai SL, Gazdar A, Pirker R, Green A, Crist W, Brodeur GM, et al: Expression of a multidrug resistance gene in human cancers. J Natl Cancer Inst 81: 116-124, 1989. 
4. Itsubo M, Ishikawa T, Toda G and Tanaka M: Immunohistochemical study of expression and cellular localization of the multidrug resistance gene product $\mathrm{P}$-glycoprotein in primary liver carcinoma. Cancer 73: 298-303, 1994

5. Lai EC, Choi TK, Cheng CH, Mok FP, Fan ST, Tan ES and Wong J: Doxorubicin for unresectable hepatocellular carcinoma. A prospective study on the addition of verapamil. Cancer 66: 1685-1687, 1990

6. Shen DW, Lu YG, Chin KV, Pastan I and Gottesman MM: Human hepatocellular carcinoma cell lines exhibit multidrug resistance unrelated to MRD1 gene expression. J Cell Sci 98: 317-322, 1991.

7. Borst P, Evers R, Kool M and Wijnholds J: A family of drug transporters, the multidrug resistance-associated proteins. J Natl Cancer Inst 92: 1295-1302, 2000.

8. Grant CE, Valdimarsson G, Hipfner DR, Almquist KC, Cole SP and Deeley RG: Overexpression of multidrug resistanceassociated protein (MRP) increases resistance to natural product drugs. Cancer Res 54: 357-361, 1994

9. Kruh GD and Belinsky MG: The MRP family of drug efflux pumps. Oncogene 22: 7537-7552, 2003.

10. Kool M, de Haas M, Scheffer GL, Scheper RJ, van Eijk MJ Juijn JA, Baas F and Borst P: Analysis of expression of cMOAT (MRP2), MRP3, MRP4, and MRP5, homologues of the multidrug resistance-associated protein gene (MRP1), in human cancer cell lines. Cancer Res 57: 3537-3547, 1997

11. Kruh GD, Zeng H, Rea PA, Liu G, Chen ZS, Lee K and Belinsky MG: MRP subfamily transporters and resistance to anticancer agents. J Bioenerg Biomembr 33: 493-501, 2001

12. Jedlitschky G, Leier I, Buchholz U, Hummel-Eisenbeiss J Burchell B and Keppler D: ATP-dependent transport of bilirubin glucuronides by the multidrug resistance protein MRP1 and its hepatocyte canalicular isoform MRP2. Biochem J 327: 305-310, 1997.

13. Zeng H, Liu G, Rea PA and Kruh GD: Transport of amphipathic anion by human multidrug resistance protein 3. Cancer Res 60: 4779-4784, 2000.

14. Schuetz JD, Connelly MC, Sun D, Paibir SG, Flynn PM, Srinivas RV, Kumar A and Fridland A: MRP4, a previously unidentified factor in drug resistance to nucleoside-based antiviral drugs. Nat Med 5: 1048-1051, 1999.

15. Wijnholds J, Mol CAAM, van Deemter L, de Haas M, Scheffer GL, Baas F, Beijnen JH, Scheper RJ, Hatse S, de Clercq E, Balzarini J and Borst P: Multidrug-resistance protein 5 is a multispecific organic anion transporter able to transport nucleotide analogs. Proc Natl Acad Sci USA 97: 7476-7481, 2000

16. Carr BI: Hepatocellular carcinoma, current management and future trends. Gastroenterology 127 (suppl 1): S218-S224, 2004

17. Nishio K, Nakamura T, Koh Y, Suzuki T, Fukumoto H and Saijo N: Drug resistance in lung cancer. Curr Opin Oncol 11: 109-115, 1999.

18. Taniguchi K, Wada M, Kohno K, Nakamura T, Kawabe T, Kawakami M, Kagotani K, Okumura K, Akiyama S and Kuwano M: A human canalicular multispecific organic anion transporter (cMOAT) gene is overexpressed in cisplatin-resistant human cancer cell lines with decreased drug accumulation. Cancer Res 56: 4124-4129, 1996.

19. Koike K, Kawabe T, Tanaka T, Toh S, Uchiumi T, Wada M Akiyama S, Ono M and Kuwano M: A canalicular multispecific organic anion transporter (cMOAT) antisense cDNA enhances drug sensitivity in human hepatic cancer cells. Cancer Res 57: 5475-5479, 1997

20. Savaraj N, Wu C, Wangpaichitr M, Kuo MT, Lampidis T, Robles C, Furst AJ and Feun L: Overexpression of mutated MRP4 in cisplatin resistant small cell lung cancer cell line: Collateral sensitivity to azidothymidine. Int J Oncol 23: 173-179, 2003.

21. Oguri T, Isobe T, Suzuki T, Nishio K, Fujiwara Y, Katoh O and Yamakido M: Increased expression of the MRP5 gene is associated with exposure to platinum drugs in lung cancer. Int $\mathbf{J}$ Cancer 86: 95-100, 2000.

22. Matsushima Y and Baba T: An antigranulomatous effect of glycyrrhizin. J Exp Pathol 6: 25-30, 1992.

23. Ganem D and Prince AM: Hepatitis B virus infection - natural history and clinical consequences. N Engl J Med 350: 1118-1129, 2004.

24. Nakabayashi H, Taketa K, Yamane T, Miyazaki M, Miyano K and Sato J: Phenotypical stability of a human hepatoma cell line, Huh-7, in long-term culture with chemically defined medium. Gann 75: 151-158, 1984
25. Sugimoto C, Fujieda S, Seki M, Sunaga H, Fan GK, Tsuzuki H, Borner C, Saito H and Matsukawa S: Apoptosis-promoting gene (bax) transfer potentiates sensitivity of squamous cell carcinoma to cisplatin in vitro and in vivo. Int J Cancer 82: 860-867, 1999.

26. Fields RD and Lancaster MV: Dual-attribute continuous monitoring of cell proliferation/cytotoxicity. Am Biotechnol Lab 11: 48-50, 1993.

27. Alcorn J, Lu X, Moscow JA and McNamara PJ: Transporter gene expression in lactating and nonlactating human mammary epithelial cells using real-time reverse transcription-polymerase chain reaction. J Pharmacol Exp Ther 303: 487-496, 2002.

28. Takeuchi A, Kaneko S, Matsushita E, Urabe T, Shimoda A and Kobayashi K: Interferon-alpha modulates resistance to cisplatin in three human hepatoma cell lines. J Gastroenterol 34: 351-358, 1999

29. Pera MF Jr and Harder HC: Analysis for platinum in biological material by flameless atomic absorption spectrometry. Clin Chem 23: 1245-1249, 1977.

30. Perez RP: Cellular and molecular determinants of cisplatin resistance. Eur J Cancer 34: 1535-1542, 1998.

31. Crul M, Schellens JH, Beijnen JH and Maliepaard M: Cisplatin resistance and DNA repair. Cancer Treat Rev 23: 341-366, 1997

32. Gately DP and Howell SB: Cellular accumulation of the anticancer agent cisplatin: a review. Br J Cancer 67: 1171-1176, 1993.

33. Scala S, Pacelli R, Iaffaioli RV, Normanno N, Pepe S, Frasci G, Genua G, Tsuruo T, Tagliaferri P and Bianco AR: Reversal of adriamycin resistance by recombinant alpha-interferon in multidrug-resistant human colon carcinoma LoVo-doxorubicin cells. Cancer Res 51: 4898-4902, 1991.

34. Kang Y and Perry RR: Modulatory effects of tamoxifen and recombinant human alpha-interferon on doxorubicin resistance. Cancer Res 53: 3040-3045, 1993.

35. Chaudhary PM and Roninson IB: Induction of multidrug resistance in human cells by transient exposure to different chemotherapeutic drugs. J Natl Cancer Inst 85: 632-639, 1993.

36. Guengerich FP: Metabolisn of chemical carcinogens Carcinogenesis 21: 345-351, 2000

37. Salinas AE and Wong MG: Glutathione S-transferases - a review. Curr Med Chem 6: 279-309, 1999.

38. Marie JP, Simonin G, Legrand O, Delmer A, Faussat AM, Lewis AD, Sikic BI and Zittoun R: Glutathione-S-transferases pi, alpha, mu and mdr1 mRNA expression in normal lymphocytes and chronic lymphocytic leukemia. Leukemia 9: 1742-1747, 1995.

39. Haga S, Hinoshita E, Ikezaki K, Fukui M, Scheffer GL, Uchiumi $\mathrm{T}$ and Kuwano $\mathrm{M}$ : Involvement of the multidrug resistance protein 3 in drug sensitivity and its expression in human glioma. Jpn J Cancer Res 92: 211-219, 2001.

40. Hirohashi T, Suzuki H and Sugiyama Y: Characterization of the transport properties of cloned rat multidrug resistance-associated protein 3 (MRP3). J Biol Chem 274: 15181-15185, 1999

41. Kool M, van der Linden M, de Haas M, Scheffer GL, de Vree JM, Smith AJ, Jansen G, Peters GJ, Ponne N, Scheper RJ, Elferink RP Baas F and Borst P: MRP3, an organic anion transporter able to transport anti-cancer drugs. Proc Natl Acad Sci USA 96: 6914-6919, 1999

42. Faneyte IF, Kristel PM and van de Vijver MJ: Multidrug resistance associated genes MRP1, MRP2 and MRP3 in primary and anthracycline exposed breast cancer. Anticancer Res 24 2931-2939, 2004

43. Young LC, Campling BG, Voskoglou-Nomikos T, Cole SP Deeley RG and Gerlach JH: Expression of multidrug resistance protein-related genes in lung cancer: correlation with drug response. Clin Cancer Res 5: 673-680, 1999.

44. Rius M, Nies AT, Hummel-Eisenbeiss J, Jedlitschky G and Keppler D: Cotransport of reduced glutathione with bile salts by MRP4 (ABCC4) localized to the basolateral hepatocyte membrane. Hepatology 38: 374-384, 2003.

45. Lee K, Belinsky MG, Bell DW, Testa JR and Kruh GD Isolation of MOAT-B, a widely expressed multidrug resistanceassociated protein/canalicular multispecific organic anion transporter-related transporter. Cancer Res 58: 2741-2747, 1998.

46. Norris MD, Smith J, Tanabe K, Tobin P, Flemming C Scheffer GL, Wielinga P, Cohn SL, London WB, Marshall GM, Allen JD and Haber M: Expression of multidrug transporter MRP4/ABCC4 is a marker of poor prognosis in neuroblastoma and confers resistance to irinotecan in vitro. Mol Cancer Ther 4: $547-553,2005$ 
47. Maher JM, Cherrington NJ, Slitt AL and Klaassen CD: Tissue distribution and induction of the rat multidrug resistanceassociated proteins 5 and 6. Life Sci 78: 2219-2225, 2006.

48. Pratt S, Shepard RL, Kandasamy RA, Johnston PA, Perry W III and Dantzig AH: The multidrug resistance protein 5 (ABCC5) confers resistance to 5-fluorouracil and transports its monophosphorylated metabolites. Mol Cancer Ther 4: 855-863, 2005.

49. McAleer MA, Breen MA, White NL and Matthews N: pABC11 (also known as MOAT-C and MRP5), a member of the ABC family of proteins, has anion transporter activity but does not confer multidrug resistance when overexpressed in human embryonic kidney 293 cells. J Biol Chem 274: 23541-23548, 1999.

50. Suzuki T, Nishio $K$ and Tanabe S: The MRP family and anticancer drug metabolism. Curr Drug Metab 2: 367-377, 2001.

51. Nies AT, Konig J, Cui Y, Brom M, Spring H and Keppler D: Expression of the multidrug resistance proteins MRP2 and MRP3 in human hepatocellular carcinoma. Int J Cancer 94: 492-499, 2001
52. Zollner G, Wagner M, Fickert P, Silbert D, Fuchsbichler A, Zatloukal K, Denk H and Trauner M: Hepatobiliary transporter expression in human hepatocellular carcinoma. Liver Int 25: 367-379, 2005

53. Dhiman RK and Chawla YK: Herbal medicines for liver diseases. Dig Dis Sci 50: 1807-1812, 2005.

54. Horikawa M, Kato Y, Tyson CA and Sugiyama Y: The potential for an interaction between MRP2 (ABCC2) and various therapeutic agents: probenecid as a candidate inhibitor of the biliary excretion of irinotecan metabolites. Drug Metab Pharmacokinet 17: 23-33, 2002.

55. Thomas H, Foster G and Platis D: Mechanisms of action of interferon and nucleoside analogues. J Hepatol 39: S93-S98, 2003.

56. Conjeevaram HS and Lok AS: Management of chronic hepatitis B. J Hepatol 38 (suppl 1): S90-S103, 2003.

57. Llovet JM and Bruix J: Systematic review of randomized trials for unresectable hepatocellular carcinoma: Chemoembolization improves survival. Hepatology 37: 429-442, 2003. 